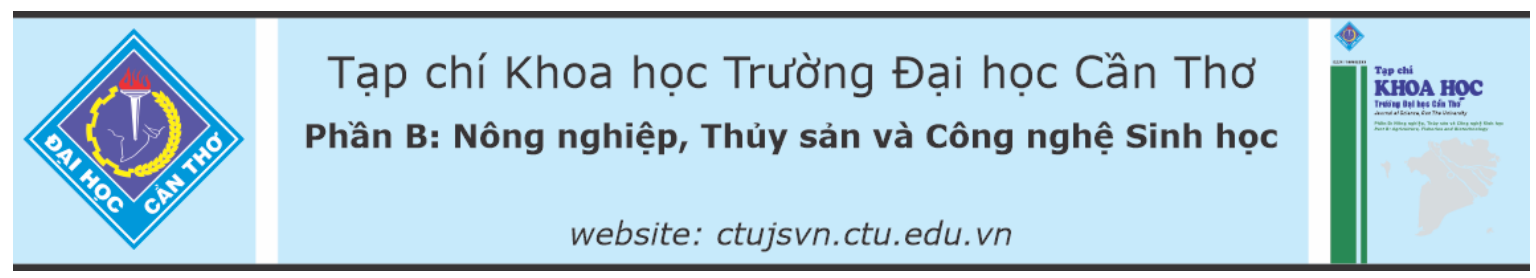

DOI:10.22144/ctu.jvn.2021.189

\title{
ĐA DANG DI TRUYỀN CỦA HỌ GENE OSHKT Ở 41 GIỐNG LÚA ĐỊA PHƯƠNG ĐỒNG BẰNG SÔNG CỦU LONG
}

Văn Quốc Giang ${ }^{1}$, Trần In Đô ${ }^{2}$, Nguyễn Văn Mạnh ${ }^{2}$, Nguyễn Thành Tâm ${ }^{3}$, Huỳnh Như Điền ${ }^{1}$, Lê Thị Hồng Thanh ${ }^{1}$ và Huỳnh Kỳ ${ }^{1 *}$

${ }^{1}$ Bộ môn Di truyền và Chọn giống cây trồng, Khoa Nông nghiệp, Truờng Đại học Cần Tho'

${ }^{2}$ Học viên cao học khóa 27, ngành Di truyền và Chọn giống

${ }^{3}$ Viện Nghiên cưu và Phát triển Đồng bằng sông Cưu Long, Truờng Đại học Cần Tho

*Nguời chịu trách nhiệm về bài viết: Huỳnh Kỳ (email: hky@ctu.edu.vn)

\section{Thông tin chung:}

Ngày nhận bài: $11 / 05 / 2021$

Ngày nhận bài sủa: 19/06/2021

Ngày duyệt đăng: 25/12/2021

\section{Title:}

The variation of OsHKT family genes in 41 Mekong delta rice varieties

\section{Tù khóa:}

Lúa dịa phuoong, OsHKT, OsHKT 1,5, OsHKT 2,1, SNP

\section{Keywords:}

Local rice, OsHKT, OsHKT 1,5, OsHKT 2,1, SNP

\begin{abstract}
OsHKT is a family of genes that play an important role in the salt tolerance mechanism of rice. In this study, DNA fragments of two gene groups OsHKTI and OsHKT2 from 41 local rice varieties in the Mekong Delta were sequenced, in order to find out the genetic relationship among them. The results showed that the polymorphism was most expressed in the two genes OsHKT1;5 and OsHKT2;1 with all of 41 rice varieties showing polymorphisms in the OsHKT1; 5 gene, and 25 rice varieties were variable in the OsHKT2;1 gene. This result is the basis for further studies on salt tolerance related to the OsHKT gene family of local rice varieties in the Mekong Delta.
\end{abstract}

\section{TÓM TẮT}

OsHKT là ho gene đóng vai trò quan trọng trong cơ chế chống chịu mặn của cây lúa. Trong nghiên cứu này, các đoạn DNA của hai nhóm gene OsHKT1 và OsHKT2 tù 41 giống lúa địa phuoong vùng $Đ B S C L$ đã được giải trình tư, nhằm tìm ra mối tuơng quan di truyền giữa các giống lúa. Kết quả cho thấy, sư đa hình được thể hiện nhiều nhất ở hai gene OsHKT1;5 và OsHKT2;1 với tất cả 41 giống lúa cho sụ đa hình ở gene OsHKT1; 5 và 25 giống lúa đối với gene OsHKT2;1. Kết quả này là cơ sở cho các nghiên cứu tiếp theo về khả năng chống chịu mặn liên quan đến họ gene OsHKT của các giống lúa địa phương vùng Đồng bằng sông Cưu Long.

\section{GIỚI THIÊUU}

Lúa gạo là loại cây lương thực đứng vị trí hàng đầu, có giá trị kinh tế cao và là một trong những nét văn hóa ẩm thực đặc trưng trong đời sống và con người Việt Nam. Tuy nhiên, tình trạng biến đổi khí hậu những năm gần đây đã và đang có những diễn biến ngày càng phức tạp, hiện tượng xâm nhập mặn kéo dài làm cho diện tích đất nông nghiệp suy giảm trầm trọng, đặc biệt là diện tích đất trồng lúa các tỉnh Đồng bằng sông Cửu Long (ĐBSCL) bị thu hẹp đáng kể. Đứng trước thực trạng đó việc nghiên cứu tìm ra giống lúa có khả năng chịu được mặn nhằm đảm bảo an toàn lương thực là vấn đề cấp thiết mà hầu hết các nhà chọn giống đã và đang rất quan tâm. Hầu hết các nghiên cứu di truyền đều tập trung vào Saltol QTL, là một trong các QTL ảnh hưởng đến khả năng chịu mặn của cây lúa, có nguồn gốc từ các giống lúa Ấn Độ như Pokkali có khả năng chịu mặn ở giai đoạn cây con (Thomson et al., 2010). Sự hiểu biết hiện tại về các cơ chế chống chịu mặn đã tạo điều kiện thuận lợi cho việc khai thác các chất vận chuyển màng định vị trong không gian (Munns \& Tester, 2008; Zhu, 2001). Các cơ chế đã biết bao gồm sự cô lập các ion trong không bào và loại trừ các ion ra khỏi rễ và lá (Munns \& Tester, 2008). Do 
đó, các biến thể allele trong trình tự của các gene vận chuyển ion có thể đóng một vai trò quan trọng trong việc cung cấp khả năng chống chịu hiệu quả với stress mặn.

Đối với cây lúa, tính trạng chống chịu mặn là một tiến trình sinh lý rất phức tạp thay đổi theo các giai đoạn sinh trưởng khác nhau của cây (Hossain et al., 2015). Sự mất cân bằng $\mathrm{Na}^{+}$và $\mathrm{K}^{+}$là một trong những nguyền nhân làm hạn chế năng suất và chính tî̉ lệ $\mathrm{Na}^{+} / \mathrm{K}^{+}$trong chồi cũng là chỉ tiêu quan trọng trong chọn lọc giống lúa chống chịu mặn (Gregorio \& Senadhira, 1993). Nhóm gene OsHKT được báo cáo là có liên quan đến khả năng chịu mặn ở lúa, vì gene $O s H K T$ mã hóa chất vận chuyển $\mathrm{Na}^{+}$hoặc $\mathrm{K}^{+}$ hoặc chất đồng vận chuyển $\mathrm{Na}^{+}-\mathrm{K}^{+}$đóng vai trò quan trọng trong tuần hoàn $\mathrm{Na}^{+}$, duy trì nồng độ $\mathrm{Na}^{+}$ và tỷ lệ $\mathrm{Na}^{+} / \mathrm{K}^{+}$ở mức thấp trong các mô, đặc biệt là ở lá (Mishra et al., 2016). Có hai nhóm OsHKT là $O s H K T 1$ và $O s H K T 2 ; 2$ (Horie et al., 2001) trong đó chất vận chuyển $\mathrm{Na}^{+}$là $O s H K T 1$ và chất vận chuyển cặp $\mathrm{Na}^{+}-\mathrm{K}^{+}$là $O s H K T 2 ; 2$, có thể hoạt động hài hòa trên lúa indica chịu mặn. Các nghiên cứu sâu hơn đã báo cáo rằng $O_{s H K T 1 ; 4}$ biểu hiện xung quanh xylem trong bẹ lá trong khi $O s H K T 1 ; 5$ biểu hiện xung quanh xylem rễ (Cotsaftis et al., 2011). Tương tự, OsHKT2;2;1 và $O s H K T 2 ; 2 ; 4$ được biểu hiện ở phần ngoài của rễ và trong lông hút (Schachtman \& Schroeder, 1994). HKT2;1 biểu hiện được điều hòa đáng kể trong vỏ rễ khi nồng độ $\mathrm{K}^{+}$thấp và nồng độ $\mathrm{Na}^{+}$cao (Almeida et al., 2013; Horie et al., 2001).

Bảng 1. Danh sách 41 giống lúa thí nghiệm
Một gene vận chuyển khác là $O s H K T 2 ; 2 ; 4$ cho thấy $93 \%$ tương đồng với $O s H K T 2 ; 2 ; 3$ và làm nhiệm vụ trung gian vận chuyển $\mathrm{K}^{+}$độc lập với nồng độ $\mathrm{Na}^{+}$ (Horie et al., 2001).

Cây phát sinh loài của mỗi họ sẽ giúp xác định được mối quan hệ tiến hóa của các thành viên với nhau. Trong mỗi họ, tồn tại các sự tương đồng liên quan chặt chẽ với nhau và các phân họ riêng biệt của chất vận chuyển $\mathrm{K}^{+}$, từ đó cho thấy có thể phân chia ra được các chức năng chuyên biệt (Amrutha et al., 2007). Việc hiểu rõ hơn về mối quan hệ giữa các gene $H K T$ có thể cung cấp thêm nhiều thông tin quan trọng cần thiết cho sự phát triển cũng như cho thấy được sự đa hình giữa các nhóm gene $O s H K T$ của các giống cây trồng chịu mặn (Bafeel, 2013). Cho đến nay, các nghiên cứu phát sinh loài trên họ gene $H K T$ còn rất hạn chế ngoại trừ công trình trước đó của (Bafeel, 2013; Gomez-Porras et al., 2012; Heidari et al., 2011; Platten et al., 2006). Đó cũng chính là lí do nghiên cứu này được thực hiện, có tất cả 6 cặp mồi được dùng kiểm tra và phân nhóm 41 giống lúa của Việt Nam trên vùng gene $H K T$ bằng cách sử dụng các trình tự nucleotide có sẵn trong cơ sở dữ liệu hiện tại.

\section{PHƯƠNG TIÊN VÀ PHƯƠNG PHÁP}

\subsection{Vật liệu nghiên cứu}

Vật liệu nghiên cứu gồm 41 giống lúa địa phương (Bảng 1$)$, và trình tự 6 cặp mồi sử dụng trong nghiên cứu này (Bảng 2 ).

\begin{tabular}{cllcll}
\hline STT & Tên giống & Nguồn gốc & STT & Tên giống & Nguồn gốc \\
\hline 1 & Đốc Phụng & Cà Mau & 22 & Lùn Phền & Cà Mau \\
2 & Lùn Cẩn Đỏ & Cà Mau & 23 & Lùn Hền & Cà Mau \\
3 & Lùn Cẩn Trắng & Cà Mau & 24 & Lùn Vàng & Cà Mau \\
4 & Bờ Liếp 2 & Cà Mau & 25 & Lùn Sữa & Bạc Liêu \\
5 & Một Bụi Đỏ Lùn CM & Cà Mau & 26 & Một Bụi Trắng & Bạc Liêu \\
6 & Một Bụi Lùn & Cà Mau & 27 & Móng Chim Đen & Bạc Liêu \\
7 & Ba Bông Mẵn & Cà Mau & 28 & Móng Chim Rơi 3 & Bạc Liêu \\
8 & Lùn Cao Sản Đỏ & Cà Mau & 29 & Ba Bụi Lùn & Bạc Liêu \\
9 & Lùn Cao Sản Trắng & Cà Mau & 30 & Tài Nguyên & Bạc Liêu \\
10 & Tài Nguyên CL & Cà Mau & 31 & Trăng Bồ Câu & Cà Mau \\
11 & Nàng Cờ Đỏ 2 & Cà Mau & 32 & Tét Rằn & Cà Mau \\
12 & Trà Long 2 & Cà Mau & 33 & Lùn Mẵn & Cà Mau \\
13 & Ba Bụi 2 & Cà Mau & 34 & Sói Lùn 1 & Bạc Liêu \\
14 & Tép Hành & Cà Mau & 35 & Ngọc Nữ & Bạc Liêu \\
15 & Năm Tài 1 & Cà Mau & 36 & Nàng Thơm & Bạc Liêu \\
16 & Một Bụi 5 & Kiên Giang & 37 & Thơm Mẵn & Bạc Liêu \\
17 & Một Bụi Đỏ CM & Cà Mau & 38 & Nàng Quớt Biển 1 & Kiên Giang \\
18 & Nàng Cum 1 & Cà Mau & 39 & Trăng Phiếu & Kiên Giang \\
19 & Lùn Phền Hạt Nhỏ & Kiên Giang & 40 & Lùn Đỏ & Kiên Giang \\
20 & Lùn Phệt & Kiên Giang & 41 & Nàng Quớt Biển & Cà Mau \\
21 & Thơm Lùn Mùa & Kiên Giang & & & \\
\hline
\end{tabular}


Bảng 2. Trình tự 6 cặp mồi SSR dùng trong nghiên cứu

\begin{tabular}{|c|c|c|c|c|c|}
\hline Tên gene & Tên primer & Trình tự (5'-3') & NST & $\operatorname{Tm}\left({ }^{0} \mathrm{C}\right)$ & Kích thước (bp) \\
\hline OsHKT1;1 & HKT1_1-F & CCAATCGTGATTCGGGGTCA & 4 & 60.11 & 770 \\
\hline \multirow[b]{2}{*}{ OsHKT1;3 } & $\begin{array}{ll}\text { HK 11_1-K } \\
\text { HKT1 3-F }\end{array}$ & AGCTCGGTAGCTTTGGATGG & \multirow[b]{2}{*}{2} & $\begin{array}{ll}60.31 \\
59.82\end{array}$ & \multirow[b]{2}{*}{875} \\
\hline & HKT1 $3-\mathrm{R}$ & TTTCAGTGGCTTGCCTGACG & & 61.17 & \\
\hline \multirow{2}{*}{ OsHKT1;5 } & HKT1_5-F & GTACCTGCAGCAAGCATGAGA & \multirow[b]{2}{*}{1} & 60.68 & \multirow[b]{2}{*}{880} \\
\hline & HKT1 ${ }^{-} 5-\mathrm{R}$ & CACGACGATAATCCGCAAGG & & 59.15 & \\
\hline \multirow{2}{*}{ OsHKT2;1 } & HKT2_1-F & TCTGAGGGTCAGATGTGGAT & \multirow{2}{*}{6} & 57.44 & \multirow{2}{*}{875} \\
\hline & HKT2_1-R & GTCACGTCTCCTCTTTGCGA & & 60.04 & \\
\hline \multirow{2}{*}{ OsHKT2;3 } & HKT2_3-F & TGCTGCCTAACTTGCAGACA & \multirow[b]{2}{*}{1} & 59.89 & \multirow{2}{*}{640} \\
\hline & HKT2 $3-\mathrm{R}$ & GTGTGCAGAAGCAATGGGTG & & 60.04 & \\
\hline \multirow{2}{*}{ OsHKT2;4 } & HKT2_4-F & GTGTGCAGAAGCAATGGGTG & \multirow{2}{*}{6} & 60.04 & \multirow{2}{*}{775} \\
\hline & HKT2_4-R & GCAGCACACTGTCCCTATGT & & 60.04 & \\
\hline
\end{tabular}

\subsection{Phương pháp nghiên cứu}

2.2.1. Đánh giá kiểu gene chịu mặn của các giống lúa

DNA của 41 giống lúa được ly trích theo phương pháp CTAB (Doyle \& Doyle, 1990). Sau quá trình ly trích, mẫu DNA được hòa tan trong $50 \mu \mathrm{TE}(\mathrm{pH}$ 8.0 ) và lưu trữ ở nhiệt độ $-20^{\circ} \mathrm{C}$.

\section{Phản úng PCR}

Mỗi phản ứng PCR bao gồm $50 \mu 1$, sử dụng bộ PCR KIT (NEXproTM Diagnostics) gồm các thành phần 10X e-Taq Buffer, $10 \mathrm{mM} \mathrm{dNTP}$, e-Taq DNA Polymerase, thêm vào nước tinh sạch, mồi và $\mathrm{DNA}$. Tất cả được trộn đều trước khi cho vào máy $\mathrm{PCR}$ (Bioer Thermal Cycler XP) và phản ứng $\mathrm{PCR}$ được thực hiện trong 35 chu kỳ gia nhiệt. Điện di sản phẩm $\mathrm{PCR}$ tinh chế bằng bộ kit Wizard $\mathrm{SV}$ Gel và PCR Clean-up System (Promega), sau đó được gửi đi giải trình tự bằng phương pháp Sanger (Sanger et al., 1977) tại công ty Phù Sa Biochem.

\section{Phưong pháp phân tích số liệu}

Kích thước sản phẩm $\mathrm{PCR}$ được tính toán bằng phần mềm GelAnalyzer 19.1 (Istvan Lazar Jr., 2019). Các cặp mồi được sử dụng trong nghiên cứu được thiết kế bằng phần mềm PRIMER 3 (Sadangi, 2015). Kết quả giải trình tự được lưu trữ ở dạng FASTA và phân tích bằng phần mềm MEGA 6 (Tamura et al., 2013). Phần mềm BEAST 2 (Bouckaert et al., 2019) được sử dụng để vẽ cây sơ đồ di truyền của 41 giống lúa so sánh với giống lúa Nipponbare dựa trên trình tự của các gene OsHKTs.

\section{KẾT QUẢ VÀ THẢO LUẬN}

\subsection{Sự đa hình gene ở nhóm OsHKT1}

Kết quả ở Hình 1 cho thấy sự đa hình trong nhóm OsHKT1 đều được chia thành 2 nhóm lớn. Đối với gene OsHKT1; 1, nhóm 1 gồm có 6 giống lúa (Lùn Cao Sản Đỏ, Trắng Bồ Câu, Lùn Mẵn, Tép Hành, Một Bụi Đỏ Cao CM, Sói Lùn 1) có xuất hiện đột biến điểm, chủ yếu là $\mathrm{C}$ thành $\mathrm{A}$. Còn lại nhóm 2 không xuất hiện đột biến. Gene OsHKT1;3, nhóm 1 có 10 giống lúa có xuất hiện đột biến điểm thay thế $\mathrm{C}$ thành $\mathrm{G}$, gồm các giống Nàng Quớt Biển, Nàng Quớt Biển 1, Năm Tài 1, Lùn Đỏ, Móng Chim Rơi 3, Bờ Liếp 2, Lùn Phền Hạt Nhỏ, Ba Bụi 2, Móng Chim Đen, Một Bụi Lùn. Tuy nhiên, sự đa hình ở nhóm OsHKT1 thể hiện rõ ở gene OsHKT1;5. Nhóm 1 có 18 giống lúa xuất hiện các SNPs bao gồm Nàng Quớt Biển 1, Lùn Cẩn Trắng, Móng Chim Rơi 3, Một Bụi Đỏ Lùn CM, Nàng Thơm, Lùn Phệt, Ba Bụi Lùn, Lùn Phền, Nàng Cờ Đỏ 2, Bờ Liếp 2, Thơm Mẵn, Một Bụi Trắng, Một Bụi 5, Lùn Phền Hạt Nhỏ, Một Bụi Lùn, Một Bụi Đỏ Cao CM, Tài Nguyên CL, Trà Long 2 , chỉ riêng giống Đốc Phụng là không có biến thể xuất hiện. Tần suất xuất hiện các biến thể ở mỗi giống dao động từ 3 đến 9 SNPs ở nhóm 1 đối với gene $O s H K T 1 ; 5$. Ở nhóm 2, tất cả 22 giống lúa đều xuất hiện biến thể với tần suất cao dao động từ 6 đến 9 SNPs (Ba Bông Mẳn, Móng Chim Đen, Lùn Mẳn, Lùn Đỏ...). Qua đây có thể nhận thấy rằng số lượng biến thể ở nhóm 2 nhiều hơn nhóm 1 , và ở nhóm $O s H K T 1$ thì gene $O s H K T 1 ; 5$ có tần suất xuất hiện biến thể cao nhất so với gene $O s H K T 1 ; 1$ và OsHKT1;3. Ngoài ra, có thể nhận thấy ở cả 3 gene OsHKT1;1, OsHKT1;3, OsHKT1;5 đều xuất hiện đột biến thay thế nucleotide $\mathrm{C}$ thành $\mathrm{G}$, nhưng tần suất xuất hiện của đột biến này ở gene $O s H K T 1 ; 5$ ít hơn 2 gene còn lại. Tuy nhiên, OsHKT1;5 có thêm sự xuất hiện của các loại đột biến thay thế khác như $\mathrm{A}>\mathrm{C}, \mathrm{A}>\mathrm{G}, \mathrm{C}>\mathrm{T}, \mathrm{G}>\mathrm{A}$, và nhiều nhất là $\mathrm{T}>\mathrm{C}$, vị trí của các biến thể ở các gene trong nhóm $O s H K T 1$ so với gene tham chiếu được thể hiện ở Bảng 3 . 
Bảng 3. Vị trí các biến thể của gene thuộc nhóm OsHKT 1 ở 41 mẫu thí nghiệm so với gene tham chiếu

\begin{tabular}{lcccc}
\hline Gene & NST & Vị trí & Allele tham chiếu & Allele thay đổi \\
\hline OsHKT1;1 & 4 & 116 & $\mathrm{C}$ & $\mathrm{A}$ \\
OsHKT1;3 & 280 & 153 & $\mathrm{C}$ & $\mathrm{G}$ \\
\hline & 306 & $\mathrm{~T}$ & $\mathrm{C}$ \\
& 338 & $\mathrm{~A}$ & $\mathrm{C}$ \\
& 397 & $\mathrm{~A}$ & $\mathrm{C}$ \\
& & $\mathrm{T}$ & $\mathrm{C}$ \\
OsHKT1;5 & 454 & $\mathrm{~A}$ & $\mathrm{G}$ \\
& & $\mathrm{G}$ & $\mathrm{A}$ \\
& & $\mathrm{G}$ & $\mathrm{A}$ \\
& & $\mathrm{T}$ & $\mathrm{C}$ \\
& 508 & $\mathrm{C}$ & $\mathrm{T}$ \\
& 566 & $\mathrm{C}$ & $\mathrm{T}$ \\
& 592 & $\mathrm{C}$ & $\mathrm{T}$ \\
& 593 & $\mathrm{~T}$ & $\mathrm{C}$ \\
& 621 & $\mathrm{~T}$ & $\mathrm{C}$ \\
\hline
\end{tabular}
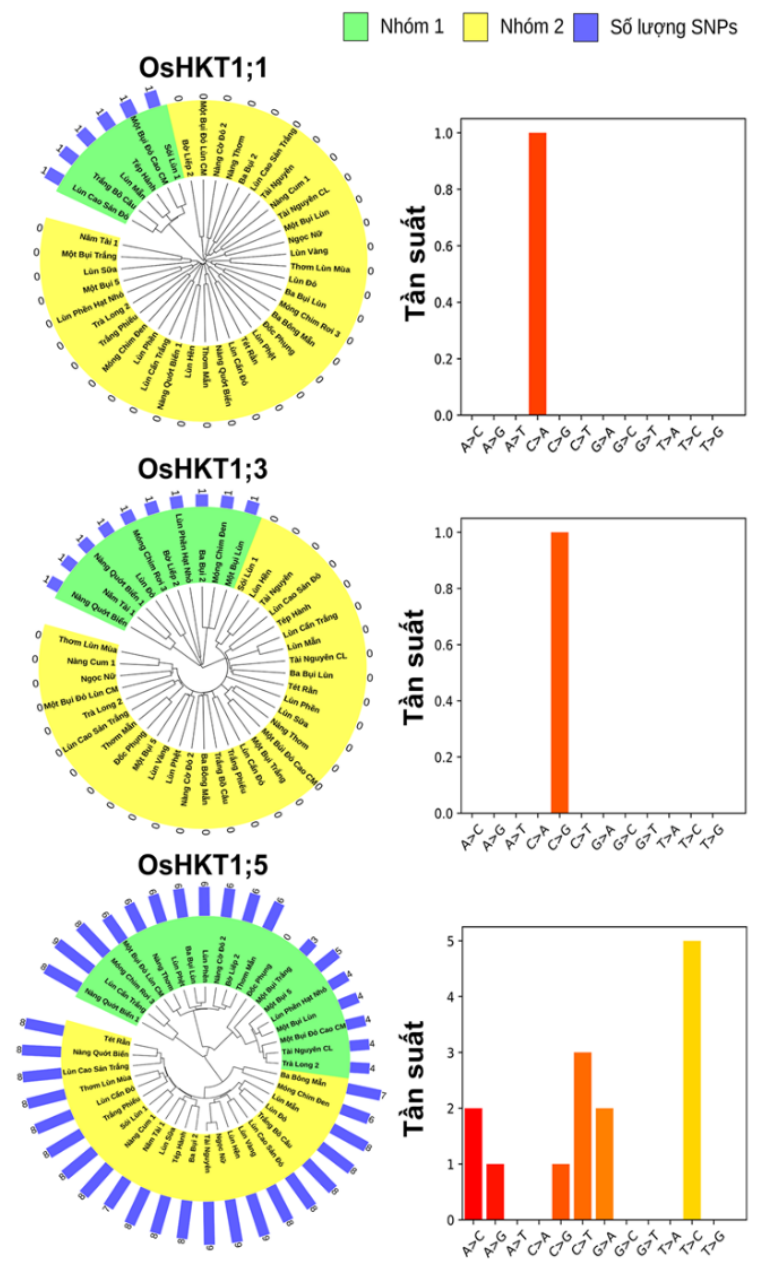

Hình 1. Biểu đồ các dạng biến thể của OsHKT1 ở 41 giống lúa ĐBSCL. A. OsHKT1;1, B. OsHKT1;3, và $O s H K T 1 ; 5$. 


\subsection{Sự đa hình gene ở nhóm OsHKT2;2}

Đối với nhóm OsHKT2 (Hình 2), sự đa hình ở gene OsHKT2;1 cũng được chia thành 2 nhóm chính. Nhóm 1 tuy có 20 giống lúa nhưng chỉ có 4 giống lúa xuất hiện SNPs (Lùn Cẩn Đỏ, Móng Chim Đen, Ba Bông Mẵn, Lùn Đỏ), trong đó Móng Chim Đen có số lượng biến thể nhiều nhất với 10 SNPs. Nhóm 2 với 21 giống lúa đều xuất hiện biến thể với tần suất cao từ 5 đến 17 SNPs, gồm Trà Long 2 , Một Bụi Trắng, Nàng Cờ Đỏ 2, Bờ Liếp 2, Năm Tài 1,
Một Bụi Lùn, Một Bụi 5, Lùn Vàng, Lùn Sữa, Tài Nguyên, Móng Chim Rơi 3, Lùn Cao Sản Trắng, Lùn Phệt, Lùn Hền, Một Bụi Đỏ Cao CM, Lùn Cẩn Trắng, Nàng Cum 1, Ba Bụi Lùn, Thơm Mẵn, Trắng Phiếu, Thơm Lùn Mùa. Trong 21 giống lúa ở nhóm 2 thì giống Lùn Sữa có số lượng biến thể cao nhất với 17 SNPs được tìm thấy. Phần lớn các biến thể xuất hiện ở gene $O s H K T 2 ; 1$ chủ yếu là dạng A thành $\mathrm{T}$ (nhiều nhất) và $\mathrm{G}$ thành $\mathrm{A}$, ngoài ra còn có các dang $\mathrm{A}>\mathrm{G}, \mathrm{C}>\mathrm{A}, \mathrm{C}>\mathrm{G}, \mathrm{C}>\mathrm{T}, \mathrm{G}>\mathrm{T}, \mathrm{T}>\mathrm{A}, \mathrm{T}>\mathrm{C}$, $\mathrm{T}>\mathrm{G}$.

Nhóm $1 \square$ Nhóm $2 \square$ Số lượng SNPS

\section{OsHKT2;1}
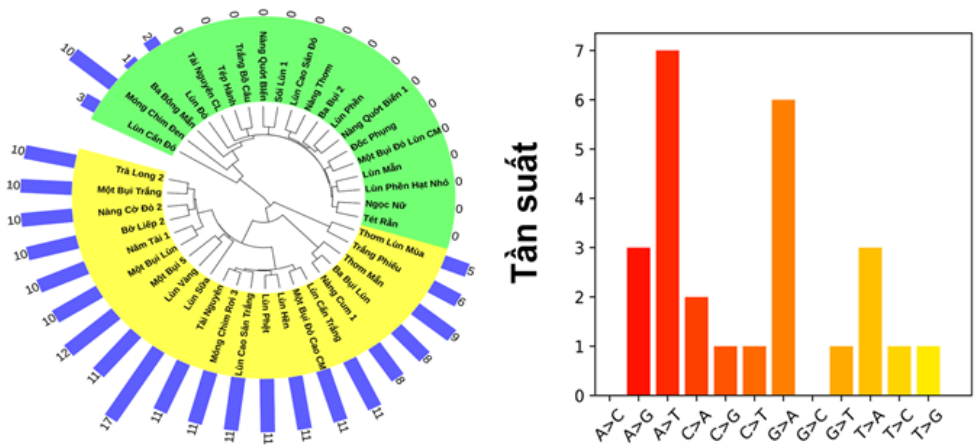

OsHKT2;3
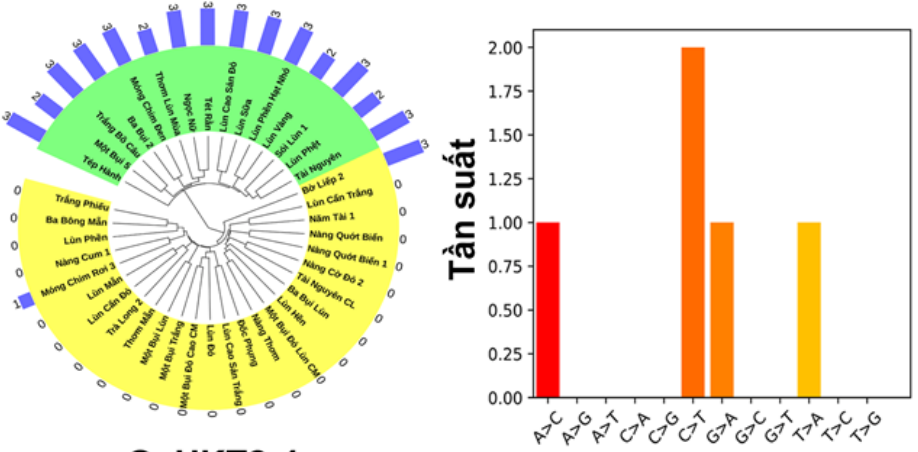

OsHKT2;4
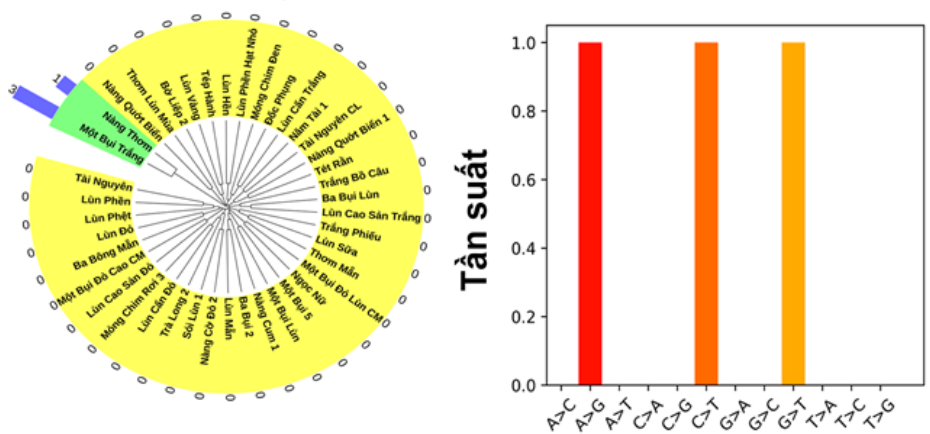

Hình 2. Biểu đồ các dạng biến thể của OsHKT2 ở 41 giống lúa ĐBSCL. A. OsHKT2;1, B. OsHKT2;3, và $O$ sHKT2;4. 
Gene OsHKT2;3 có 15 giống lúa (Tép Hành, Một Bụi 5, Trắng Bồ Câu, Ba Bụi 2, Móng Chim Đen, Thơm Lùn Mùa, Ngọc Nữ, Tét Rằn, Lùn Cao Sản Đỏ, Lùn Sữa, Lùn Phền Hạt Nhỏ, Lùn Vàng, Sói Lùn 1, Lùn Phệt, Tài Nguyên) với số lượng biến thể xuất hiên từ 2 đến 3 SNPs. Nhóm 2 mặc dù có 26 giống lúa nhưng chỉ có duy nhất một giống lúa xuất hiện biến thể là Móng Chim Rơi 3. Các dạng biến thể xuất hiện ở gene OsHKT2;3 gồm $\mathrm{A}>\mathrm{C}$, $\mathrm{C}>\mathrm{T}, \mathrm{G}>\mathrm{A}, \mathrm{T}>\mathrm{A}$ trong đó $\mathrm{C}>\mathrm{T}$ có tần suất xuất hiện cao nhất so với các dạng biến thể khác. Vị trí các SNPs ở nhóm gene OsHKT2 được thể hiện qua Bảng 4.

Bảng 4. Vị trí các SNPs ở nhóm gene OsHKT2 ở 41 giống lúa so với gene tham chiếu

\begin{tabular}{|c|c|c|c|c|}
\hline Gene & NST & $\begin{array}{l}\text { Vị } \\
\text { trí }\end{array}$ & $\begin{array}{c}\text { Allele } \\
\text { tham chiếu }\end{array}$ & $\begin{array}{c}\text { Allele } \\
\text { thay đổi }\end{array}$ \\
\hline \multirow{23}{*}{$\begin{array}{c}\text { OsHK } \\
\text { T2;1 }\end{array}$} & \multirow{23}{*}{6} & 11 & $\mathrm{~T}$ & $\mathrm{G}$ \\
\hline & & 31 & $\mathrm{~T}$ & A \\
\hline & & 32 & A & $\mathrm{T}$ \\
\hline & & 58 & A & $\mathrm{T}$ \\
\hline & & 59 & $\mathrm{~T}$ & A \\
\hline & & 60 & A & $\mathrm{T}$ \\
\hline & & 79 & G & A \\
\hline & & 118 & $\mathrm{C}$ & A \\
\hline & & 171 & G & A \\
\hline & & 223 & G & A \\
\hline & & 224 & A & $\mathrm{G}$ \\
\hline & & 403 & G & A \\
\hline & & 404 & A & $\mathrm{T}$ \\
\hline & & 472 & G & A \\
\hline & & 473 & A & $\mathrm{T}$ \\
\hline & & 633 & $\mathrm{C}$ & $\mathrm{G}, \mathrm{A}$ \\
\hline & & 634 & $\mathrm{~T}$ & $\mathrm{C}$ \\
\hline & & 672 & G & A \\
\hline & & 692 & G & $\mathrm{T}$ \\
\hline & & 711 & $\mathrm{C}$ & $\mathrm{T}$ \\
\hline & & 725 & A & $\mathrm{T}, \mathrm{G}$ \\
\hline & & 726 & $\mathrm{~T}$ & A \\
\hline & & 818 & A & $\mathrm{T}, \mathrm{G}$ \\
\hline \multirow{6}{*}{$\begin{array}{l}\text { OsHK } \\
\text { T2;3 }\end{array}$} & \multirow{6}{*}{1} & 185 & $\mathrm{C}$ & $\mathrm{T}$ \\
\hline & & 259 & G & A \\
\hline & & 261 & A & $\mathrm{C}$ \\
\hline & & 428 & $\mathrm{C}$ & $\mathrm{T}$ \\
\hline & & 511 & $\mathrm{~T}$ & A \\
\hline & & 600 & $X$ & $\mathrm{G}$ \\
\hline \multirow{3}{*}{$\begin{array}{c}\text { OsHK } \\
\text { T2;4 }\end{array}$} & \multirow{3}{*}{6} & 226 & $\bar{C}$ & $\mathrm{~T}$ \\
\hline & & 239 & A & $\mathrm{G}$ \\
\hline & & 507 & G & $\mathrm{T}$ \\
\hline
\end{tabular}

Ngoài ra, ở nhóm OsHKT2, gene OsHKT2;4 chỉ có duy nhất 2 giống lúa xuất hiện biến thể là Một Bụi Trắng và Nàng Thơm, dao động từ 1 đến 3
SNPs. So với các gene ở nhóm OsHKT1, OsHKT2;4 ở nhóm OsHKT2 có số lượng SNPs ít nhất.

Theo nghiên cứu của Cui et al. (2017), các gene như OsHKT1;1, OsHKT1;3, OsHKT2;3, và OsHKT2;4 sẽ được biểu hiện chủ yếu ở lá. Trong khi đó, OsHKT1;5, OsHKT2;1 và OsHKT2;2 sẽ biểu hiện ở cả lá và rễ. Ngoài ra, cấp độ phiên mã của nhóm OsHKT thường được điều hòa bởi $\mathrm{ABA}$ ở lá hoặc rễ்; tuy nhiên hoạt động này sẽ xảy ra ở cả lá và rễ் đối với hai gene $O s H K T 1 ; 3$ và $O s H K T 1 ; 5$ (Cui et al., 2017; Munns \& Tester, 2008; Roy et al., 2014). Nghiên cứu của (Mishra et al., 2016) đã cho thấy rằng $50 \mathrm{SNPs}$ xuất hiện ở các nhóm $O s H K T 1$ và $O s H K T 2 ; 2$ đều liên quan đến khả năng chống chịu mặn ở lúa, cụ thể là ảnh hưởng đến hoạt động của $\mathrm{Na}^{+}$và $\mathrm{K}^{+}$, trong đó $5 \mathrm{SNPs}$ xuất hiện ở vùng promoter của gene $O s H K T 2 ; 1$ cho thấy sự liên kêt chặt đến tính trạng chống chịu mặn. Kết quả Hình 1 và Hình 2 cho thấy rằng sự xuất hiện của các biến thể ở 41 giống lúa dùng trong nghiên cứu rất có khả năng cao liên quan đến cơ chế chống chịu mặn, đặc

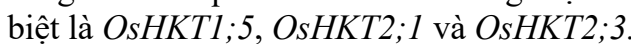

\section{KẾT LUẬN}

Kết quả thí nghiệm bước đầu đã chỉ ra được sự đa hình của các gene OsHKT1;1, OsHKT1;3, OsHKT1;5, OsHKT2;2;1, OsHKT2;2;3, OsHKT2;2;4 ở 41 giống lúa dùng trong thí nghiệm. Trong đó, sự đa hình thể hiện nhiều nhất ở gene $O s H K T 1 ; 5$, kế tiếp là gene $O s H K T 2 ; 1$. Đây sẽ là hai gene chủ lực trong nghiên cứu về khả năng chống chịu mặn cho các thí nghiệm về sau.

\section{LỜI CẢM TẠ}

Nghiên cứu được tài trợ bởi dự án Nâng cấp Trường Đại học Cần Thơ VN14-P6 (vốn vay ODA từ chính phủ Nhật Bản).

\section{TÀI LIỆ THAM KHẢO}

Almeida, P., Katschnig, D., \& de Boer, A. H. (2013). HKT transporters--state of the art. Int J Mol Sci, 14(10), 20359-20385. doi:10.3390/ijms141020359

Amrutha, R. N., Sekhar, P. N., Varshney, R. K., \& Kishor, P. B. K. (2007). Genome-wide analysis and identification of genes related to potassium transporter families in rice (Oryza sativa L.). Plant Science, 172(4), 708-721. doi:https://doi.org/10.1016/j.plantsci.2006.11.019

Bafeel, S. (2013). Phylogeny of the Plant Salinity Tolerance Related HKT Genes. Intl. J. Biol., 5, 64-68. doi:10.5539/ijb.v5n2p64

Bouckaert, R., Vaughan, T. G., Barido-Sottani, J., Duchêne, S., Fourment, M., Gavryushkina, A., 
Heled, J., Jones, G., Kühnert, D., De Maio, N., Matschiner, M., Mendes, F. K., Müller, N. F., Ogilvie, H. A., du Plessis, L., Popinga, A., Rambaut, A., Rasmussen, D., Siveroni, I., Suchard, M. A., Wu, C. H., Xie, D., Zhang, C., Stadler, T., \& Drummond, A. J. (2019). BEAST 2.5: An advanced software platform for Bayesian evolutionary analysis. PLOS Computational Biology, 15(4), e1006650. doi:10.1371/journal.pcbi.1006650

Cotsaftis, O., Plett, D., Johnson, A. A., Walia, H., Wilson, C., Ismail, A. M., Close, T. J., Tester, M., \& Baumann, U. (2011). Root-specific transcript profiling of contrasting rice genotypes in response to salinity stress. Mol Plant, 4(1), 25 41. doi: $10.1093 / \mathrm{mp} / \mathrm{ssq} 056$

Cui, L., He, Y., Li, Y., \& Xie, X. (2017). Expression patterns of OsHKT genes in rice. Chinese Journal of Rice Science, 31, 559-567. doi:10.16819/j.1001-7216.2017.7070

Doyle, J. J., \& Doyle, J. L. (1990). Isolation of plant DNA from fresh tissue. Focus, 12(1):13-15.

Gomez-Porras, J., Riaño Pachón, D. M., Benito, B., Haro, R., Sklodowski, K., Rodríguez-Navarro, A., \& Dreyer, I. (2012). Phylogenetic Analysis of $\mathrm{K}+$ Transporters in Bryophytes, Lycophytes, and Flowering Plants Indicates a Specialization of Vascular Plants. Frontiers in Plant Science, 3, 167. doi:10.3389/fpls.2012.00167

Gregorio, G. B., \& Senadhira, D. (1993). Genetic analysis of salinity tolerance in rice (Oryza sativa L.). Theoretical and Applied Genetics, 86(2), 333-338. doi:10.1007/BF00222098

Heidari, P., Falaknaz, M., Mehrabi, A., Kahrizi, D., \& Yari, K. (2011). Phylogenetic Study of HKTGene in Gramineae via Insilico cDNA-AFLP Analysis. American Journal of Scientific Research, 19, 6-12.

Horie, T., Yoshida, K., Nakayama, H., Yamada, K., Oiki, S., \& Shinmyo, A. (2001). Two types of HKT transporters with different properties of $\mathrm{Na}+$ and $\mathrm{K}+$ transport in Oryza sativa. Plant $J$, 27(2), 129-138. doi:10.1046/j.1365313x.2001.01077.x

Hossain, H., Rahman, M. A., Alam, M. S., \& Singh, R. K. (2015). Mapping of Quantitative Trait Loci Associated with Reproductive-Stage Salt Tolerance in Rice. Journal of Agronomy and Crop Science, 201(1), 17-31. doi:https://doi.org/10.1111/jac.12086

Istvan Lazar Jr., P., \& Istvan Lazar Sr., PhD. (2019). GelAnalyzer (Version 19.1). Retrieved from http://www.gelanalyzer.com/index.html
Mishra, S., Singh, B., Panda, K., Singh, B. P., Singh, N., Misra, P., Rai, V., \& Singh, N. K. (2016). Association of SNP Haplotypes of HKT Family Genes with Salt Tolerance in Indian Wild Rice Germplasm. Rice (New York, N.Y.), 9(1), 15. doi:10.1186/s12284-016-0083-8

Munns, R., \& Tester, M. (2008). Mechanisms of Salinity Tolerance. Annual Review of Plant Biology, 59(1), 651-681. doi:10.1146/annurev.arplant.59.032607.092911

Platten, J. D., Cotsaftis, O., Berthomieu, P., Bohnert, H., Davenport, R. J., Fairbairn, D. J., Horie, T., Leigh, R. A., Lin, H. X., Luan, S., Mäser, P., Pantoja, O., Rodríguez-Navarro, A., Schachtman, D. P., Schroeder, J. I., Sentenac, H., Uozumi, N., Véry, A. A., Zhu, J. K., Dennis, E. S., \& Tester, M. (2006). Nomenclature for HKT transporters, key determinants of plant salinity tolerance. Trends Plant Sci, 11(8), 372-374. doi:10.1016/j.tplants.2006.06.001

Roy, S. J., Negrão, S., \& Tester, M. (2014). Salt resistant crop plants. Current Opinion in Biotechnology, 26, 115-124. doi:https://doi.org/10.1016/j.copbio.2013.12.004

Sadangi, C. (2015). Primer design using Primer3 software.

Sanger, F., Nicklen, S., \& Coulson, A. R. (1977). DNA sequencing with chain-terminating inhibitors. Proc Natl Acad Sci US A, 74(12), 5463-5467. doi:10.1073/pnas.74.12.5463

Schachtman, D. P., \& Schroeder, J. I. (1994). Structure and transport mechanism of a highaffinity potassium uptake transporter from higher plants. Nature, 370(6491), 655-658. doi:10.1038/370655a0

Tamura, K., Stecher, G., Peterson, D., Filipski, A., \& Kumar, S. (2013). MEGA6: Molecular Evolutionary Genetics Analysis Version 6.0. Molecular Biology and Evolution, 30(12), 27252729. doi:10.1093/molbev/mst197

Thomson, M. J., de Ocampo, M., Egdane, J., Rahman, M. A., Sajise, A. G., Adorada, D. L., Tumimbang-Raiz, E., Blumwald, E., Seraj, Z. I., Singh, R. K., Gregorio, G. B., \& Ismail, A. M. (2010). Characterizing the Saltol Quantitative Trait Locus for Salinity Tolerance in Rice. Rice, 3(2), 148-160. doi:10.1007/s12284-010-9053-8

Zhu, J. K. (2001). Plant salt tolerance. Trends Plant Sci, 6(2), 66-71. doi:10.1016/s13601385(00)01838-0 